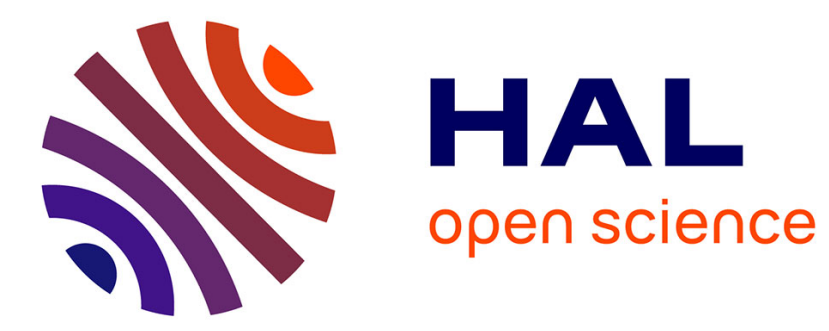

\title{
Educational Tools to Teach Design Students the Dynamic Behaviours of Smart Materials
}

Agnese Piselli, Sara Colombo, Jenny Faucheu, David Delafosse Delafosse, Barbara Del Curto

\section{To cite this version:}

Agnese Piselli, Sara Colombo, Jenny Faucheu, David Delafosse Delafosse, Barbara Del Curto. Educational Tools to Teach Design Students the Dynamic Behaviours of Smart Materials. DRS Learn X Design 2019, Jul 2019, Ankara, Turkey. 10.21606/learnxdesign.2019.17033 . emse-02879953

\section{HAL Id: emse-02879953 https://hal-emse.ccsd.cnrs.fr/emse-02879953}

Submitted on 17 Aug 2020

HAL is a multi-disciplinary open access archive for the deposit and dissemination of scientific research documents, whether they are published or not. The documents may come from teaching and research institutions in France or abroad, or from public or private research centers.
L'archive ouverte pluridisciplinaire HAL, est destinée au dépôt et à la diffusion de documents scientifiques de niveau recherche, publiés ou non, émanant des établissements d'enseignement et de recherche français ou étrangers, des laboratoires publics ou privés. 


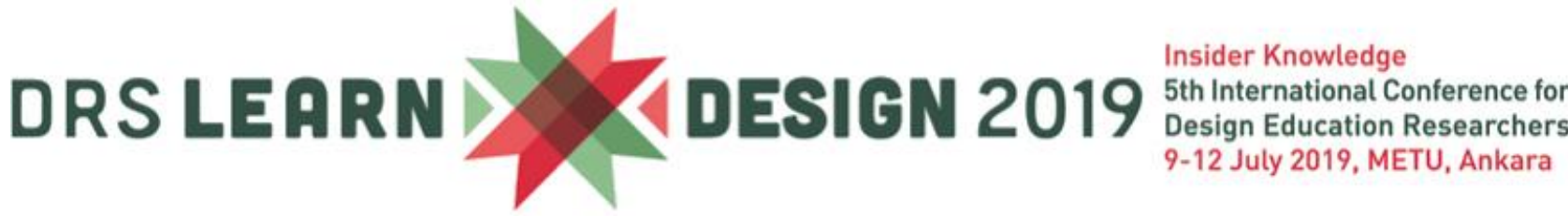

\section{Educational Tools to Teach Design Students the Dynamic Behaviours of Smart Materials}

\author{
Agnese PISELLI \\ Politecnico di Milano, Dipartimento CMIC "Giulio Natta" \\ agnese.piselli@polimi.it \\ Sara COLOMBO \\ MIT Design Lab \\ scolombo@mit.edu \\ Jenny FAUCHEU \\ Mines Saint-Etienne, CNRS, Laboratoire Georges Friedel \\ jenny.faucheu@mines-stetienne.fr

\section{David DELAFOSSE} \\ Mines Saint-Etienne, CNRS, Laboratoire Georges Friedel \\ david.delafosse@mines-stetienne.fr

\section{Barbara DEL CURTO} \\ Politecnico di Milano, Dipartimento CMIC “Giulio Natta” \\ Barbara.delcurto@polimi.it
}

doi: 10.21606/learnxdesign.2019.17033

\begin{abstract}
Materials teaching is part of a paradigm shift currently happening in the design education. It has become crucial to provide design students with an up-to-date knowledge about the latest advance in materials and manufacturing technologies with the aim to prepare them to more effectively cope with the next industry challenges. The introduction of smart materials started to revolutionize the way we design and interact with products. Their dynamic properties are changing our perception and understanding about what a material is in itself (a system), and especially, what it is able to do (its performance). This paper presents a multidisciplinary framework for teaching functional materials based on a 5-layer structure: from the material science basics (1), materials engineering (2), stimuli-responsive phenomena (3), material experience (4) and product experience (5). Among the research outputs, four design-oriented tools are described. Apart from an introductory lecture, descriptive cards provide information on the most common phenomena that describe commercial smart materials application (levels 1-3). The Smart Materials for Sensory Experiences Map (SM4SE) classifies such materials based on their input/output stimuli and puts them into relation with the explorative sensory modalities (levels 3-4). By selecting an application of smart materials, the Dynamic Product Experience tool encourages students to explore, describe and qualitatively rank the dimensions of product experience (usefulness, desirability, credibility, understandability, usability) (level 5). The tools have been tested in a one-week learning experience focused on smart materials teaching
\end{abstract}


within the Material Selection Criteria course in Design \& Engineering at Politecnico di Milano. As an output of the full immersion, twenty-eight case studies on dynamic products were collected by students.

Keywords: material systems; smart materials; material experience; transdisciplinarity; design engineering

\section{The Shifting Notion of Materiality}

The study of materials, their individual properties and related fabrication processes, is an essential element in the education of a product designer. Materials are at the core of any physical artefact, and do not only contribute to its function, but also have aesthetic and emotional values which allow the designer to shape the character of a product (Figuerola, Lai \& Ashby, 2016; Karana \& Hekkert, 2010). With the rapid advancements in research and technology, the field of materials is constantly evolving, meaning that designers have to stay up to date, to not miss out on new opportunities that might present a solution to their next design problem (Hölter, Piselli, Colombo \& Del Curto, 2019; Karana, Pedgley, Rognoli \& Korsunsky, 2016).

The introduction of smart materials started to revolutionize the way we design and interact with products. Their dynamic properties are changing our perception and understanding about what a material is in itself (a system), and especially what it is able to do (its performance). Materials are no longer just static dead mass, but became something that is alive - and so will be the future products that we incorporate them in (Hölter et al., 2019)

The study of materials and products that exhibit dynamically changing properties in response to external stimuli has especially caught the interest of designers that work in the fields of interaction design, more specifically humancomputer interaction $(\mathrm{HCl})$, which focuses on the intersection between the digital and physical world. The growing complexity and invisibility of technologies inherent in today's products, that came with the movement of Ubiquitous Computing and the Internet of Things (IOT), have led to a dematerialization of content and information, with which people are interacting on a daily basis (Brownell, 2014; Parisi et al., 2018). In this sense, the use of smart materials generates new opportunities in creating future forms of interaction, promoting the concepts of material move (Fernaeus \& Sundström, 2012), material turn (Wiberg \& Robles, 2010), material lens ( Wiberg, 2016; Jung, Wiltse, Wiberg \& Stolterman, 2017), and dynamic products (Colombo, 2014). Under the vision of tangible bits (Ullmer \& Ishii, 2000), designers started to explore Tangible User Interfaces (TUIs) that incorporate smart materials and technologies. Creating engaging user experiences in physical interactions with the digital world, and thus bridging the gap between material and immaterial, has therefore become a new challenge for designers (Arnall, 2014).

This change in the notion of materiality, which is represented by the closing gap between what is material and what is immaterial, is also being explored under the umbrella of “Computational Composites" (Vallgårda \& Sokoler, 2010). Based on their temporal and responsive nature, smart materials and computational composites that change their properties over time and in context, were, later on, also described as "Becoming Materials" (Bergström et al., 2010). Most recently, connecting the material and immaterial world, the class of ICS Materials (Parisi et al., 2018) was defined, referring to Interactive, Connected and Smart materials that are overpassing conventional smart materials by inheriting additional degrees of intelligence. They are described as "composite entities in which artificial intelligence and materiality can be qualitatively combined" (Parisi et al., 2018), and said to present reciprocity of action and reaction with user and environment through variability (meaning that the material's response is reversible and contextual), the possibility of being programmed or combined (through physical as well as digital means) and the ability to connect by transferring and/or receiving data (not only via a digital network).

As materials are currently part of a paradigm shift, from being the physicality of a product (Rojter, 2011) to representing a phygital layer that drives the experience with it ( Hekkert \& Karana, 2014; Bergamaschi, Lefebvre, Colombo, Del Curto \& Rampino, 2016; Wang, Li, Liu \& Liu, 2019), it is prerogative of material courses to develop new tools and methodologies of teaching such disciplines to design students (Del Curto \& Pedeferri, 2010).

\section{Framework to Teach Smart Materials for Design}

Smart or functional materials have the unique ability to respond and adapt to the environment, providing energytransforming functions and changing their properties in response to external stimuli, such as light, temperature, stress, moisture, magnetic fields or electric current (Addington \& Schodek, 2005). Through their dynamic behaviour, they offer novel possibilities for designers, especially when it comes to the design of interactions and experiences. To take advantage of smart material behaviours, it becomes fundamental to have knowledge of their material science 
basics, their properties, both technical and expressive-sensorial ones ( Rognoli, 2010; Piselli, Baxter, Simonato, Del Curto \& Aurisicchio, 2018), and their commercial application (Lefebvre, Piselli, Faucheu, Delafosse \& Del Curto, 2014). To provide basic knowledge and encourage the use of traditional smart materials in product design, informative tools and material-driven design practices have been developed (Barati, Giaccardi \& Karana, 2018; Bengisu \& Ferrara, 2018; Bergamaschi et al., 2016; Colombo, 2016; Parisi et al., 2018).

Despite this, there is still no evidence of a systematic framework for teaching technical properties and dynamic behaviours of functional materials in design courses. This research exploits the potentials of four learning tools tailormade to integrate smart materials teaching in Materials for Design courses, with the aim of lowering the gap between theoretical fundamentals of such materials (material science and engineering ground) and dynamic products development process (design practice). A 5-layer framework was used to structure an introductory lecture on functional materials and to design the Descriptive cards, the Sensory Experiences Map (SM4SE) and the Dynamic Product Experience tool.

\subsection{Introductory Lecture - Layers 1-5}

In the context of materials teaching, the information provided on material properties are different and calibrated to course contents and students' background. The approaches to materials teaching in the engineering and industrial design field differ in terms of language, purpose and information details (Piselli, Simonato \& Del Curto, 2016). In general, materials science and engineering courses provide students with a detailed theoretical ground on composition, structures, technical properties, manufacturing processes and rational methods of materials selection (Ashby, 1992; Farag, 2002). On the other hand, industrial designers are more familiar with a hands-on approach. For this reason, at the Design Faculty of Politecnico di Milano, materials science is approached by merging lectures with practical exercises, using material selection software (e.g., Cambridge Engineering Selector) and web resources coupled with the involvement of the materials library physical resources to allow students to build a physical/sensorial experience with materials (Del Curto \& Pedeferri, 2010).

While these methods are effective in teaching designers the fundamentals of traditional material classes, such as ceramics and glasses, metals, polymers, natural materials (wood, paper) and textiles, smart materials represent a multifaceted topic to be approached in teaching as it blurs the boundaries between matter and behaviour. Dynamic products that implement smart materials are both highly technical and highly experiential artefacts. Like with traditional materials, product designers are expected to be proficient with all these dimensions. Our objective was thus to provide students with a practical framework to deconstruct existing dynamic products that use smart materials, so that they could get acquainted with them through case studies. To achieve this, the amount and variety of information that characterize functional materials was structured into five different layers (Figure 1), from materials science basics to user experience.

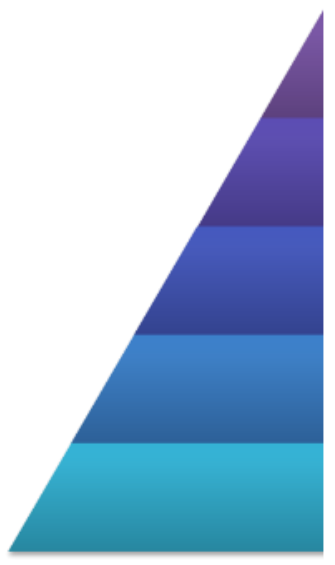

\section{Materials science}

\section{Materials engineering}

\section{Stimuli responsive phenomenon}

\section{Material experience}

\section{Product experience}

\begin{tabular}{l}
\hline - which are the main components of the SM? \\
- what physical phenomena are involved? \\
\hline - how the SM are processed? \\
- which technical prop. characterise the SM? \\
\hline - which stimuli are involved? \\
- what is the magnitude of the change? \\
- how fast the transition is? Is it reversible or programmable? \\
\hline - what senses are involved in the material experience? \\
- what expressive-sensorial and symb. assoc. does it trigger? \\
\hline - is the product context of use influenced by the stimuli- \\
responsive character of the material(s) employed?
\end{tabular}

Figure 1. Framework to structure the large amount of information available on smart materials

In describing them, a case study of a cooking pan that integrates a colour changing thermo-spot is provided (Figure 2). For a given smart material, Layer 1 relates to the materials science basics, namely the composition, structure, physical mechanisms involved (e.g. a shift of the electron distribution towards the atoms is modified by temperature). Layer 2 focuses on the engineering aspects and aims at connecting the smartness carried by smart materials to the technical and manufacturing properties of traditional inert materials (e.g. the thermochromic pigments are deposited on the metal surface by PVD and coated by a food-contact Teflon film, that also provide durability to detergents and food 
chemicals). The focus of Layer 3 is on the transition phenomenon that characterizes a smart material as the link between an input and an output (e.g. the input stimulus is temperature change while the output is a colour variation. The change in colour from yellow to red is immediate and reversible). Layer 4 is dedicated to material experience, as the experiences that users have with and through materials at the sensorial (e.g., hard, smooth, fluffy, etc.), expressive (e.g., elegant, high-quality, natural, etc.) and emotional level (e.g., surprising, disgusting, etc.) (e.g. the surprising colour change is faint and continuous). Layer 5 focuses on product experience: the dynamic character of the product elicited by the use of a smart material can strongly influence the perception the user has of it. The pan is perceived as a high-technological product. Thanks to the thermochromic spot users can improve their healthy cooking experience. The limited use of fat allowed by the Teflon coating has a detrimental side-effect on olfactive and sound sensorial feedbacks during cooking, traditionally used for adjusting the heating power. The colour changing visual indicator compensates for this loss in a very natural and intuitive way.

This framework, developed from the collaboration of Politecnico di Milano ("Giulio Natta" Department) and Mines Saint-Etienne ("Georges Friedel" Laboratory), has been applied in an introductory lecture within Material Selection Criteria course in Design \& Engineering at Politecnico di Milano. The lecture focused first on the description of functional materials characteristics and properties (Levels 1-3). Different smart material samples were provided during the lesson in order to practically explore their expressive and sensorial dimensions (Level 4). At last, commercial applications of these functional materials were shown (Level 5) both from the engineering sector (e.g. automotive, biomedical, ICT, robotics, etc.) and the product design field (e.g. fashion and jewelry, lighting).

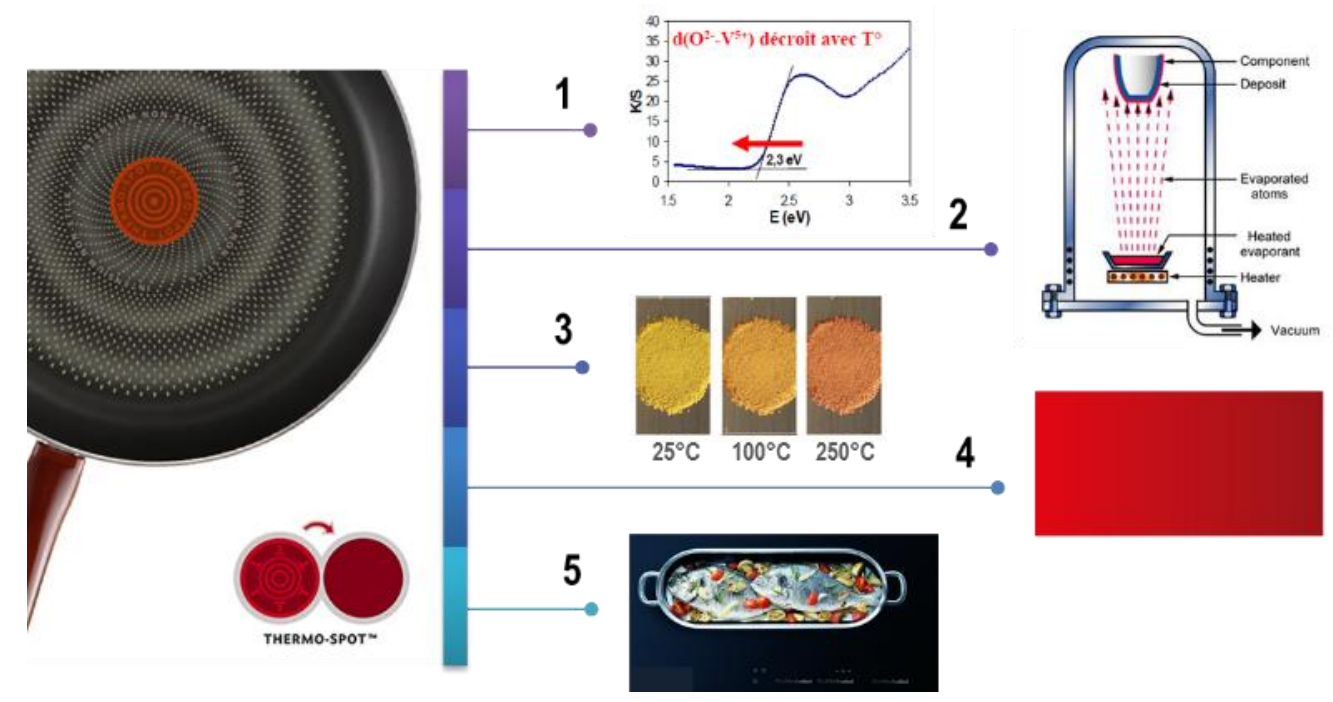

Figure 2. Practical example of the framework

\subsection{Descriptive Cards - Layers 1-3}

Functional materials can be classified based on their stimuli-responsive phenomena (Lefebvre et al., 2014). By confronting the common characteristics of the various types of phenomena (immediacy, transiency, self-actuation, directness and selectivity) (Addington \& Schodek, 2005; Kamila, 2013; Piselli, Garbagnoli, Cavarretta \& Del Curto, 2015) and by analysing examples of stimuli-responsive materials application, we can highlight that transiency and selfactuation are the core characteristics of smart materials in product design (Bengisu \& Ferrara, 2018; Ferrara \& Bengisu, 2013). A set of descriptive cards (Figure 3), presented in short text and simple icons, have been developed as a visual learning tool. They illustrate the main features of different transition phenomena, considered the working principles of the most popular smart materials. 


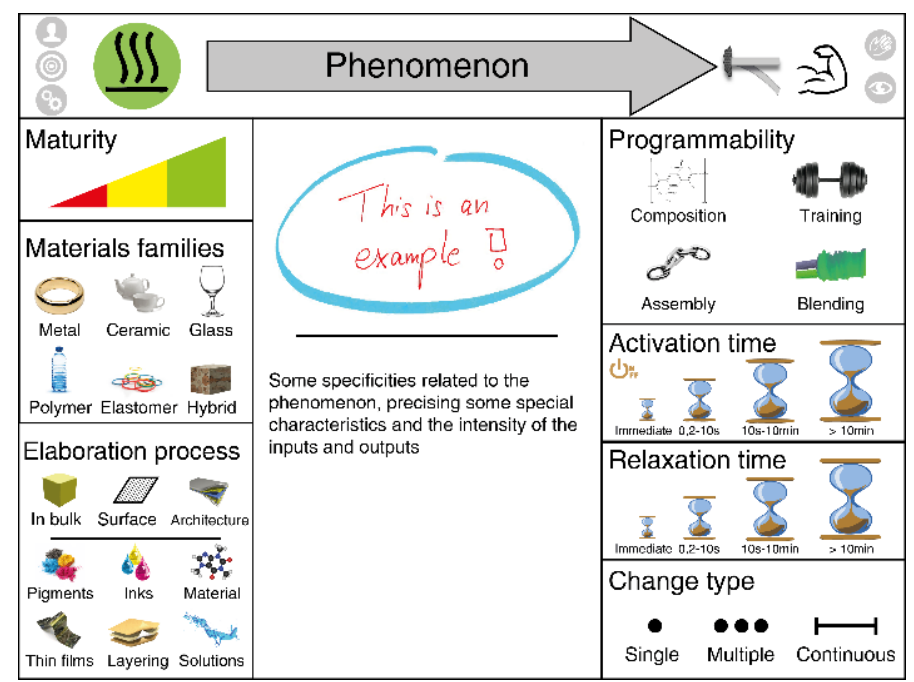

Figure 3. Descriptive card layout

The cards comprise the following information:

- Transition phenomenon, environmental input (on the left) and output (on the right). The type of input and output that characterise the phenomenon, represented by symbols, are linked together with an arrow containing the stimuli-responsive name. If the arrow is single-headed, the stimuli-responsive phenomenon is mono-directional. If it is double-headed, the stimuli-responsive phenomenon is bi-directional. Near the input/output symbols, additional information about the sources that can activate the change and the senses by which the user can perceive it are provided.

- Maturity Level. Correlated to the application of functional materials, it represents a simplified estimation of their Technology Readiness Level (TRL). Following the European Commission definition (European Commission, 2015), three categories are highlighted, "In Labs" in red colour (TRL 1-4), "Prototypes" in yellow (TRL 5-7) and "Industrialized" in green (TRL 8-9).

- Material families, Elaboration process. It represents the material classes that can be functionalized and the manufacturing/finishing processes used to implement the stimuli-responsive phenomenon.

- Programmability, activation and relaxation time, change type (single, multiple or continuous). These describe the inherent requirements and technical capabilities that characterize the stimuli-responsive phenomenon. Programmability is defined as the way to fine tune the effect (e.g., by changing the material composition, blending different pigments, by treatments ...). Activation and relaxation time (immediate, short, moderate and long) section represent the phenomenon transformation speed. If an "on-off" symbol is present in this section, that means the functional material needs a stimulus to return to its initial state.

- Application example and additional notes.

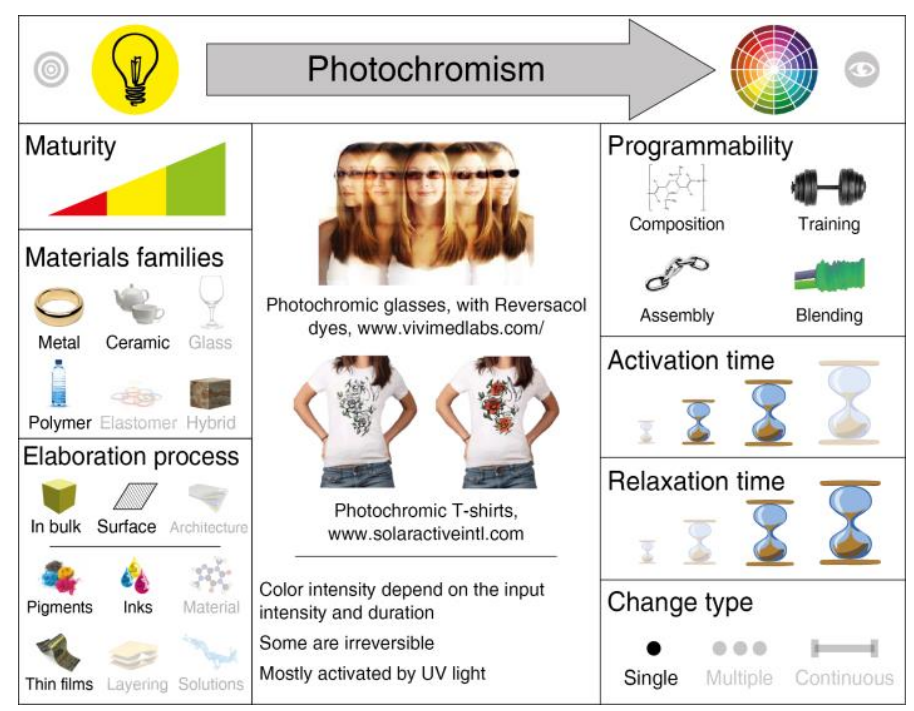

Figure 4. Example of the photochromism phenomena descriptive card 


\subsection{Smart Materials for Sensory Experiences Map (SM4SE) - Layers 3-4}

After presenting the main characteristics of the principal classes of smart materials, design students are introduced to the potentials elicited by functional materials through sensory exploration. Elaborating on the formalism of Materials Experience (Karana, Pedgley \& Rognoli, 2014; Karana et al., 2016) and merging two previous mapping studies on dynamic products (Colombo, 2014) and smart materials (Lefebvre et al., 2014), a new map has been developed with the aim to inform and inspire design students to integrate smart materials in developing dynamic objects. The Smart Materials for Sensory Experiences (SM4SE) is an input-output map (Figure 5) that consists of four circular layers:

- Input. Seven different inputs that activate the smart materials changing behaviours are identified: magnetic fields, electric fields, light, concentration (or presence) of chemicals, pressure, deformation, temperature.

- Smart Materials. Twenty-seven smart materials that directly affect the user's sensory experience (they can be perceived by the senses) have been selected. Functional materials that transform light energy into electric energy were not included, for instance.

- Product. Nine simplified dynamic sensory stimuli information were selected based on the changes supported by the selected smart materials. Namely, the product's dynamic features displayed are: colour, light, shape, physical sound, vibration, pressure, temperature, viscosity, natural aroma.

- Senses. Sensory modalities involved in the perception of product's dynamic features.

The SM4SE design tool, validated in a workshop performed with 24 students from the first year of Design \& Engineering Master's Course (Politecnico di Milano), represents a practical aid for the designers who are looking for technical solutions to be adopted for dynamic products' implementation: "However, in order for the tool to be effective, designers would benefit also from more detailed knowledge on smart materials' features and applications. For this reason, authors developed specific lectures about smart materials and dynamic products to couple with the SM4SE map, in order to give designers a background knowledge useful for the design of such products.." (Bergamaschi et al., 2016, p. 18).

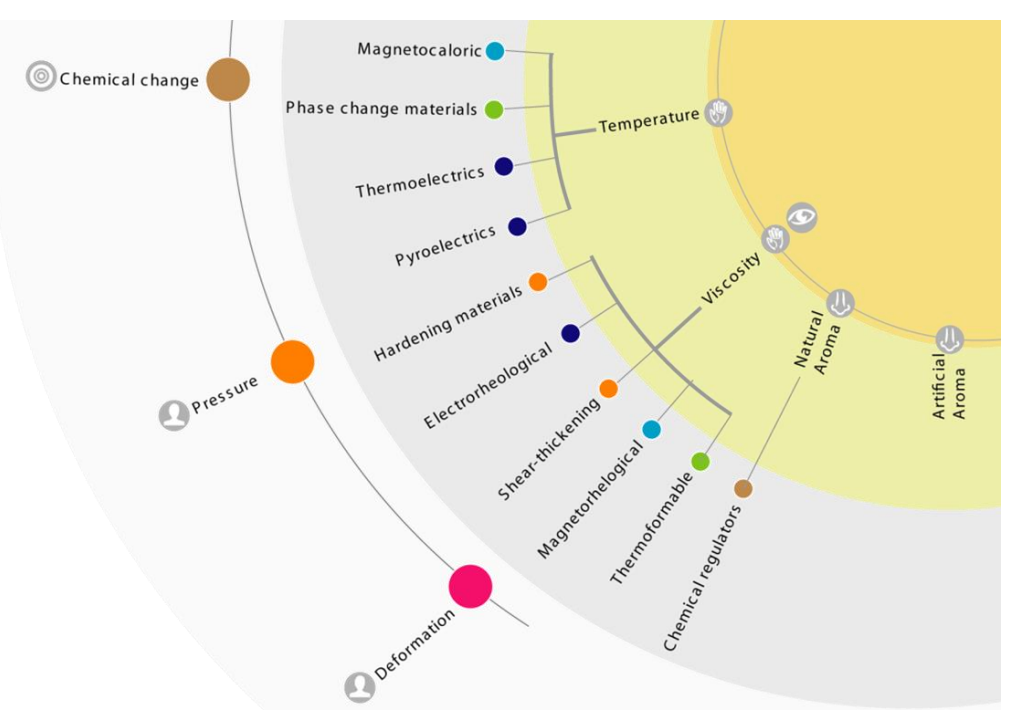

Figure 5. Detail of the Smart Materials for Sensory Experiences (SM4SE) Map (Bergamaschi et al., 2016)

\subsection{Dynamic Product Experience Tool - Layer 5}

After providing tools to explore the 4 different dimensions of smart materials (material science basics (1), materials engineering (2), stimuli-responsive phenomena (3), material experience (4)), design students are encouraged to explore Layer 5 (product experience). Adapting the work of Peter Morville (Morville, 2004), a pioneer in the field of user experience (UX), and considering the variable characteristics of smart materials, five descriptive factors of the dynamic qualities of smart products have been selected (usefulness, desirability, credibility, understandability and usability). The Dynamic Product Experience tool, inspired by other material experience tools ( Van Kesteren, Stappers, \& De Bruijn, 2007; Karana \& Hekkert, 2010), consists of a checklist of 27 qualitative attributes that can be ranked by a 3-point scale for single valence attributes (e.g., intuitive) or a 5-point scale for dual valence attributes (e.g. unattractive vs. attractive). The list of dynamic qualities and attributes was defined and discussed with two experts on smart materials (material engineering background) and two experts on product design experience. 
Design students are called to use the tool to reflect upon the desired experiences: they fill a list that summarizes the qualities and sensorial attributes desired in a smart dynamic product, and that would represent the distinctive qualities of a smart dynamic product compared to other products. An example of a filled-in list is given in Figure 6 . The aim of the Dynamic Product Experience tool, indeed, is to discuss the sensorial interaction with the dynamic product by offering topics that refer to aspects of the experience with smart materials.

\section{EX.1.5 | USER EXPERIENCE}

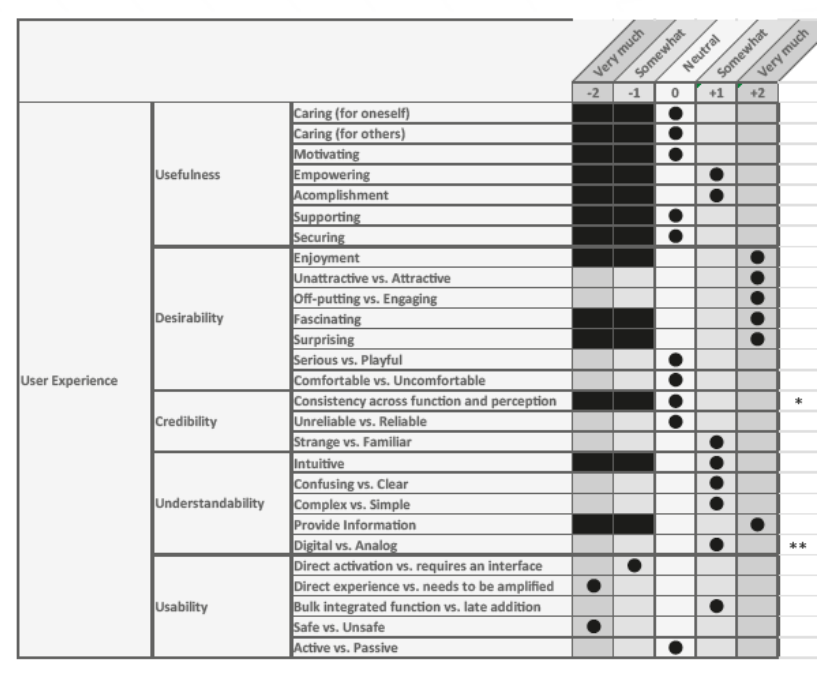

Figure 6. Example of a filled-in Dynamic Product Experience analysis grid

\section{Using the Framework in an Educational Context}

To get insights on the appropriation of the framework, Design \& Engineering students of the Material Selection Criteria course (A.Y. 2016/2017) were involved. Students were called to work on a research project focused on an existing dynamic and/or interactive product that implements one or more functional materials. The research project, submitted under the form of a report, was carried out in groups of 2 or 3 students.

Like in the example of the thermochromic pan presented during the lecture, students had to explore the smart material features addressing the 5 layers approach. In particular, students were introduced to a qualitative evaluation of product experience (in a virtual way) by choosing a smart product and deconstructing it following the five layers based on data collected on the internet. 28 project reports were collected as an output. No specific quantitative instruction had been given, neither on the length of these reports, neither on the balance between technical and experiential information. Figures 7 and 8 display examples of the produced reports. They are representative of the collected reports in terms of length, combination of text and illustrations, and balance across the 5 layers. Overall, the reports were 6 to 12 pages long, combining text, photographs and schematics. The text development for each layer was between 50 and 400 words long per layer, with a good balance of information across layers. The information structure provided by the descriptive cards and SM4SE map were almost systematically used by students to describe layers 3 and 4, seldom for layers 2 and 5, and never for layer 1 . The proposed framework was successful at fostering a balanced analysis of the case studies across all five dimensions, and the attributes classification proposed by the descriptive cards was effective at organising the information specific to stimuli-responsive materials. 

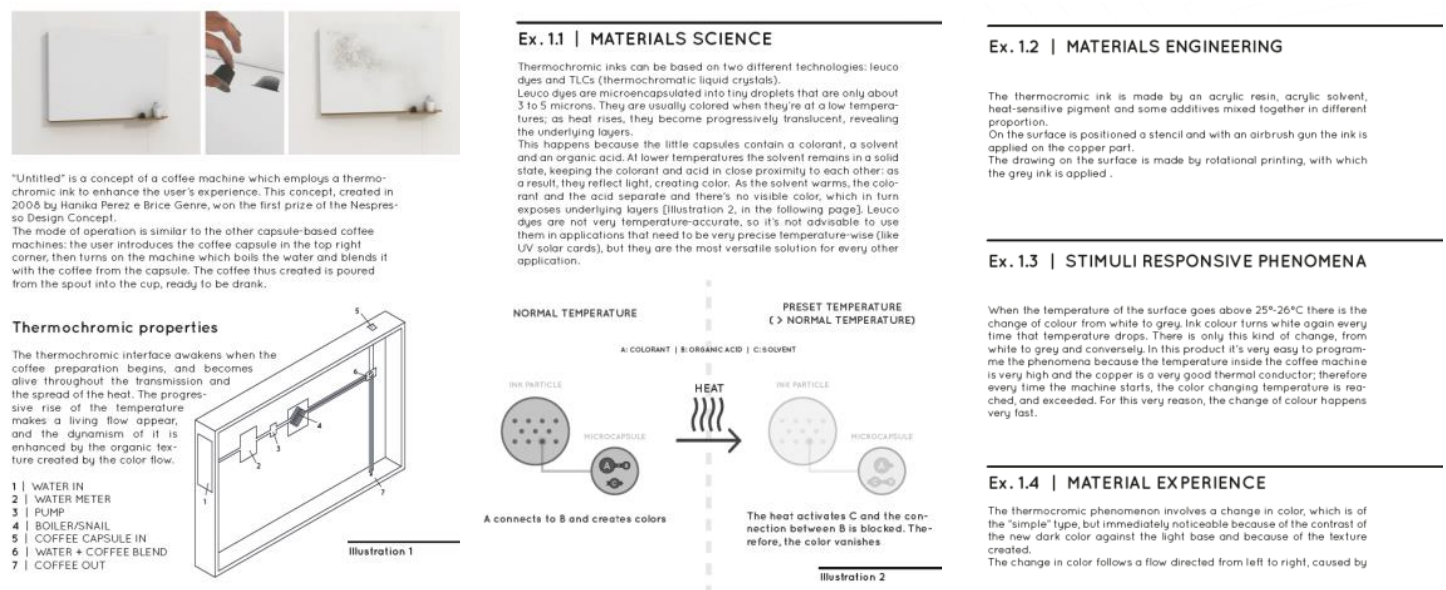

Figure 7. Report from Design \& Engineering students (2017) on the "Untitled" concept of coffee machine

In this section, the deconstruction of the smart product "RHEl clock" by Damjan Stanković and Marko Pavlović, is presented as an example. The smart product was analysed by two groups of students. The "RHEI clock" uses a ferrofluid material to display the time: the use of such functional material gives an organic movement to the numbers when they change as time flows (Figure 8). In order to qualitatively evaluate the information gathered into each layer, the textual contents of the reports were analysed in terms of word frequencies. Each layer of the deconstruction reports has been analysed separately.

\section{Layer 1. Materials science}

The two reports clearly exhibit similarities in word frequency occurrence: the words "magnetic" and "particles" have been used to describe the physical mechanisms involved in the RHEI clock together with the nouns "field" and "liquid".

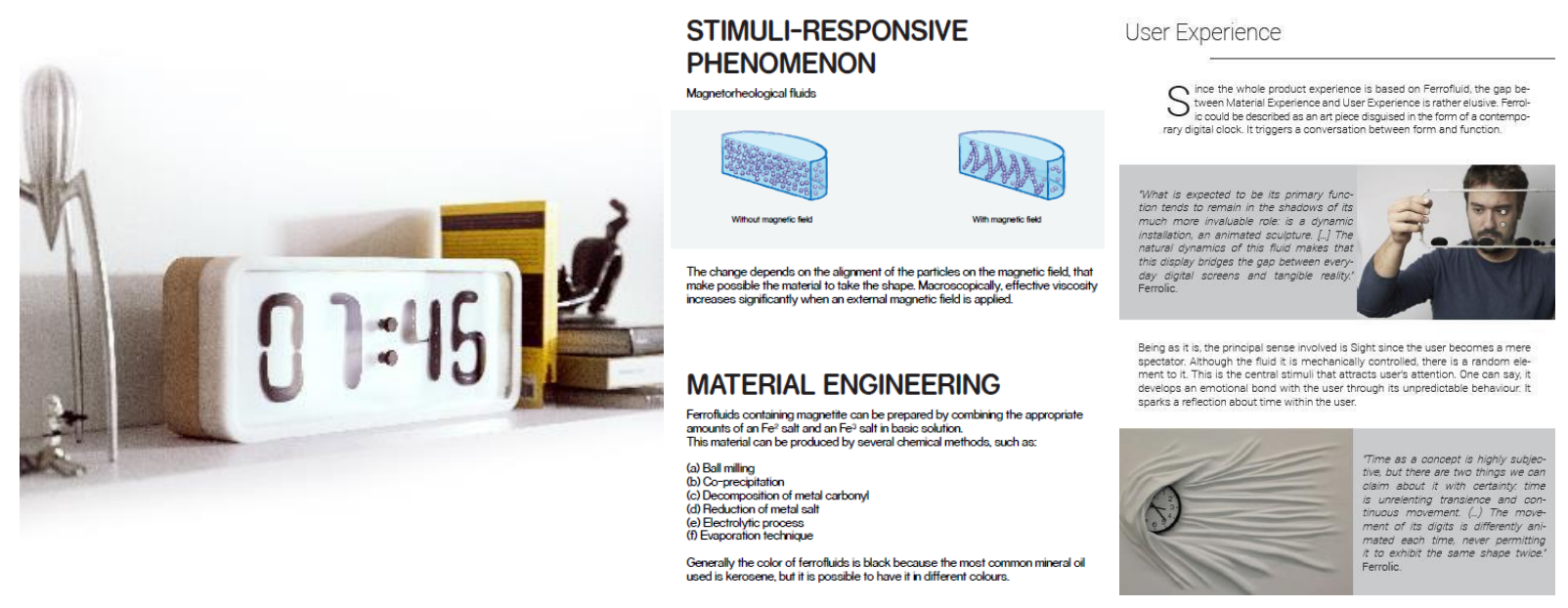

Figure 8. Pages from two different reports on the deconstruction of the RHEI clock in the 5-layers framework

\section{Layer 2: Material engineering}

Among the most cited words to describe the technical properties of the smart material used in the dynamic product selected are the chemical symbol for iron ("Fe"), and the nouns "metal", "salt", "liquid" and "magnetic".

\section{Layer 3: Stimuli-responsive phenomena}

The input parameter detected by the students has been clearly described by using the words "magnetic" and "field". The output does not clearly appear but might be brought to mind with the words "shape", "change" and "liquid" for instance.

\section{Layer 4: Material experience}

The material experience of the RHEI clock is expressed by numerous adjectives that have similar frequencies in both reports. However, it can be noticed that some groups of words relate to similar lexical field: for example, one related to the movement comprises the words "transience", "continuous", "movement", "flow", "dynamics", "position" and 
"transitions". A lexical field related to nature also appears with the words "natural", "living", "organism" and "molecules". And finally, a field related to art is represented with the words "symbolizes", "sculptures", "aesthetics", "artistic", fashion" and "attractive". Based on this analysis, the material experience related to the smart dynamic product selected could be described as dynamic, artsy and living.

\section{Layer 5: Product experience}

This layer is dedicated to the product rather than material experience. The boundary between these two layers can be blurry for some products, in particular when the primary interaction with the product relies on the smart material. In the case of the RHEI clock, some interesting nouns were depicted as related to emotions and attention: "fascinates", "emotional", "playful", sense", "spectator", "attention", "expected" and "subjective".

The analysis of the textual contents of the student reports gives insights on the type of words that are used to describe each layer. It could be useful to have additional reports to consolidate the insights collected based on these two student reports. However, it was observed that similar lexical fields can be extracted from the reports. For the engineering layers, the similarities between the data collected are very high. For the upper layers, a larger number of words have been used, but still remain in the same lexical field. In order to structure the textual information from these upper layers, an interpretative framework that proposes seven criteria has been tested. These criteria are the ones used by Morville (2004) for digital user experience. For each criterion, descriptors are given and five levels are proposed (two positive levels in green, one neutral level -black line- and two negative levels in red). From these observations, one may infer that the framework helps students at shaping the user experience associated to a material they cannot experience directly. These first anecdotal observations are currently being documented by a systematic investigation of the student reports by text mining and ontological classification methods derived from those used in semantic web research.

\section{Discussion and Conclusion}

As other materials, smart materials are also characterized by technical as well as sensorial properties. However, the added value of smart materials lies in their ability to dynamically change these properties. In many cases, changes in the technical material properties are used to improve products in terms of their functional performance, but for designers, variations in the sensorial properties of materials are especially interesting, because these can affect the product's sensory language. The sensory language (Krippendorff \& Butter, 2008) of a product, such as its form, color or texture, carries meanings and communicates messages to the user (similar to the meaning of materials discussed earlier), but it is usually static.

Through the use of smart materials designers are able to implement dynamic sensory features (Bergamaschi et al., 2016) within physical products, which then can dynamically change their sensory language, allowing the communication of simple and intuitive messages to the user in a physical way and without the need for verbal, iconic or numeric language. This new class of products was coined as dynamic products (Colombo, 2014; 2016) and defined as artefacts with sensory features (visual, tactile, auditory and olfactory) that change in a proactive and reversible way over time, in response to external or internal stimuli, addressing one or more user's sensory modalities.

With the material and immaterial world moving closer together, and GUIs like touch screens becoming the dominating element in product-user interactions, the exploration of alternative ways to transfer and display information is of increasing interest, especially within the design and $\mathrm{HCl}$ community. Physical, multi-sensorial interactions are more effective in eliciting emotions and in creating engaging user experiences, which makes smart materials and their dynamic sensorial properties a promising solution (Colombo, 2014; 2016).

Aiming at encouraging the learning and use of smart materials in designing more engaging user experiences, new tools have been developed for teaching smart material properties and behaviors to design students. In particular, the framework presented in this work, was evaluated by Design \& Engineering students as an effective tool to think about the large amount of data concerning smart materials both from the technical side (material science and engineering) and the behavioural dimension (user-centred design). It has to be noted that, in a first effort to separate the contributions to the overall dynamic product experience and facilitate their analysis by students, the performative level of materials experience, as rationalized in the Material Driven Design (MDD) method (Giaccardi \& Karana, 2015; Karana, Barati, Rognoli \& Laan, 2018), was possibly overlooked. In the proposed framework, the materials experience level is limited to psycho-sensory attributes, while those related to interactions and user exploration are separated in the analysis and moved to the next layer (user experience). Indeed, during tutored research sessions, numerous questions regarding this formal separation were raised by students. In the reports, this layer was more focused on 
products than on materials. While being effective at providing a practical approach for deconstructing complex interactions into a balanced account of their technical and experiential attributes, the present method might undermine an important aspect of smart materials, namely their ability to deliver emphatic user-product interactions seamlessly. Specific research on this aspect of smart materials versus traditional information sensing, processing and display systems is currently being carried out by the authors. This will hopefully allow to elaborate on the MDD approach and propose specific developments related to smart materials.

This paper is part of an ongoing collaboration among three research groups, in which one of the research questions addressed is "how to teach smart materials to impulse the development of innovative smart products?". By structuring these data, the knowledge resources can be used by both design practitioners and engineers as a bridging tool to set a common language in case of co-creation actions. This framework acts as a mediation artefact. It is complementary to existing knowledge resources that are adapted to professional habits of either creative industries (materials' library, books on materials with inspirational iconographic contents) or engineering concerns (technical data sheets, databases, books on materials with numerical contents). It has been shown that the structure of the framework is easily comprehended by students from design and engineering fields.

\section{References}

Addington, M., \& Schodek, D.L. (2005). Smart Materials and New Technologies for the Architecture and Design Professions. Oxford: Architectural Press.

Arnall, T. (2014). Exploring “immaterials”: Mediating design's invisible materials. International Journal of Design, 8(2), 101-117.

Ashby, M. (1992). Material Selection in Mechanical Design. Cambridge: Pergamon Press.

Barati, B., Giaccardi, E., \& Karana, E. (2018). The Making of Performativity in Designing [ with ] Smart Material Composites. In Proceedings of the SIGCHI Conference on Human Factors in Computing Systems - CHI'18 (pp. 1-11). https://doi.org/10.1145/3173574.3173579

Bengisu, M., \& Ferrara, M. (2018). Materials that Move. In SpringerBriefs in Applied Sciences and Technology (pp. 538). https://doi.org/10.1007/978-3-319-76889-2_2

Bergamaschi, S., Lefebvre, E., Colombo, S., Curto, B. Del, \& Rampino, L. (2016). Material and Immaterial: New product experience. International Journal of Designed Objects, 10(1), 11-22.

Bergström, J., Clarka, B., Frigo, A., Mazé, R., Redströma, J., \& Vallgårda, A. (2010). Becoming materials: Material forms and forms of practice. Digital Creativity, 21(3), 155-172. https://doi.org/10.1080/14626268.2010.502235

Brownell, B. (2014). From matter to x-matter: Exploring the newfound capacities of information-enhanced materials. Materials and Design, 90, 1238-1247. DOI: 10.1016/j.matdes.2015.03.027

Colombo, S. (2014). Sensory Experiences: Informing, Engaging and Persuading through Dynamic Products. (Tesi di dottorato) Politecnico di Milano.

Colombo, S. (2016). Exploring dynamic products by case studies. In Springer Briefs in Applied Sciences and Technology (pp. 47-62). DOI: 10.1007/978-3-319-33117-1_4

Del Curto, B., \& Pedeferri, M.P. (2010). A new educational approach in Design faculty for teaching Materials science. In EDULEARN10: International Conference on Education and new learning technlomogies (pp. 114-121).

European Commission. (2015). Technology readiness levels ( TRL ). HORIZON 2020. DOI: 10.15713/ins.mmj.3

Farag, M.M. (2002). Quantitative methods of materials selection. In M. Kutz (Ed.), Handbook of Materials Selection. (pp. 3-24). New York: John Wiley \& Sons.

Fernaeus, Y., \& Sundström, P. (2012). The material move how materials matter in interaction design research. In DIS '12 Proceedings of the Designing Interactive Systems Conference (p. 486-495). DOI: 10.1145/2317956.2318029

Ferrara, M., \& Bengisu, M. (2013). Materials that Change Color. Smart Materials, Intelligent Design. Milano: Politecnico di Milano - Springer.

Figuerola, M., Lai, Q., \& Ashby, M. (2016). The CES EduPack Products, Materials and Processes Database - A White Paper. Granta Teaching Resources, Cambridge.

Giaccardi, E., \& Karana, E. (2015). Foundations of Materials Experience: An Approach for HCl. In Proceedings of the 33rd Annual ACM Conference on Human Factors in Computing Systems (pp. 2447-2456). New York, NY: ACM. DOI: $10.1145 / 2702123.2702337$

Hekkert, P., \& Karana, E. (2014). Designing Material Experience. In E. Karana, O. Pedgley, \& V. Rognoli (Eds.) Materials Experience: Fundamentals of Materials and Design (pp. 3-13). DOI: 10.1016/B978-0-08-099359-1.00001-1

Hölter, M., Piselli, A., Colombo, S., \& Del Curto, B. (2019). A material database framework to support the design of shape-changing product. In Proceedings of the 2nd International Conference on Intelligent Human Systems Integration (IHSI 2019): Integrating People and Intelligent Systems. February 7-10, 2019, San Diego, California, USA DOI: 10.1007/978-3-030-11051-2_98 
Jung, H., Wiltse, H., Wiberg, M., \& Stolterman, E. (2017). Metaphors, materialities, and affordances: Hybrid morphologies in the design of interactive artifacts. Design Studies, 53, 24-46. DOI: 10.1016/j.destud.2017.06.004

Kamila, S. (2013). Introduction, classification and applications of smart materials: An overview. American Journal of Applied Sciences, 10(8), 876-880. DOI: 10.3844/ajassp.2013.876.880

Karana, E., Barati, B., Rognoli, V., \& van der Laan, A.Z. (2018). Material Driven Design. International Journal of Design, 46(10), 4223-4232. DOI: 10.1080/00927872.2017.1392540

Karana, E., \& Hekkert, P. (2010). User-Material-Product Interrelationships in Attributing Meanings. International Journal of Design, 4(3), 43-52.

Karana, E., Pedgley, O., \& Rognoli, V. (2014). Introduction to Materials Experience. In E. Karana, O. Pedgley, \& V. Rognoli (Eds.), Materials Experience (pp. xxv-xxxiii). Boston: Butterworth-Heinemann.

Karana, E., Pedgley, O., Rognoli, V., \& Korsunsky, A. (2016). Emerging material experiences. Materials and Design, 90, 1248-1250. DOI: 10.1016/j.matdes.2015.07.042

Krippendorff, K., \& Butter, R. (2008). Semantics: Meanings and contexts of artifacts. In N.J. Schifferstein, \& P Hekkert (Eds.) Product Experience (pp. 353-376). DOI: 10.1016/B978-008045089-6.50017-4

Lefebvre, E., Piselli, A., Faucheu, J., Delafosse, D., \& Del Curto, B. (2014). Smart materials: development of new sensory experiences through stimuli responsive materials. In P. Ciuccarelli, S. Maffei, P. Magaudda, G. Pellegrino, M. Perrotta, F. Trabucco, \& P. Volonté (Eds.), 5th STS Italia Conference A Matter of Design: Making Society through Science and Technology (pp. 367-382). Milan, Italy. Retrieved from http://www.stsitalia.org/?p=1548

Morville, P. (2004). User experience honeycomb. Web Log Post. Retrieved from http://Semanticstudios. Com/Publications/Semantics/000029.Php.

Parisi, S., Spallazzo, D., Ferraro, V., Ferrara, M., Ceconello, M.A., Garcia, C.A., \& Rognoli, V. (2018). Mapping ICS Materials: Interactive, Connected, and Smart Materials. In W. Karwowski \& T. Ahram (Eds.), Intelligent Human Systems Integration (pp. 739-744). Cham: Springer International.

Piselli, A., Baxter, W., Simonato, M., Del Curto, B., \& Aurisicchio, M. (2018). Development and evaluation of a methodology to integrate technical and sensorial properties in materials selection. Materials and Design (5 September 2018), 259-272. DOI: 10.1016/j.matdes.2018.04.081

Piselli, A., Garbagnoli, P., Cavarretta, G., \& Del Curto, B. (2015). The shape of light: An interactive approach to smart materials. In Proceedings of the International Conference on Engineering Design, ICED (Vol. 9).

Piselli, A., Simonato, M., \& Del Curto, B. (2016). Holistic approach to materials selection in professional appliances industry. In S. Marjanović, D.; Štorga, M.; Pavković, N.; Bojčetić, N.; Škec (Ed.), Proceedings of the 14th International Design Conference, DESIGN2016 (Vol. DS 84, pp. 865-874). Cavtat, Dubrovnik: The Design Society.

Rognoli, V. (2010). A broad survey on expressive-sensorial characterization of materials for design education. METU Journal of The Faculty of Architechure, 27(2), 287-300.

Rojter, J. (2011). Developing sustainability consciousness in engineering curriculum through materials education. In Energy Procedia (Vol. 16, pp. 810-815). DOI: 10.1016/j.egypro.2012.01.130

Ullmer, B., \& Ishii, H. (2000). Emerging frameworks for tangible user interfaces. IBM Systems Journal, 39(3.4), 915-931. DOI: $10.1147 /$ sj.393.0915

Vallgårda, A., \& Sokoler, T. (2010). A material strategy: Exploring material properties of computers. International Journal of Design, 4(3).

Van Kesteren, I., Stappers, P., \& De Bruijn, S. (2007). Defining user-interaction aspects for materials selection: three tools. In P. Ullmark \& S. Ilstedt Hjelm (Eds.), Design Inquiries: The Nordic Design Research Conference (pp. 1-10)

Wang, W.Y., Li, J., Liu, W., \& Liu, Z. (2019). Integrated computational materials engineering for advanced materials: A brief review. Computational Materials Science, 158(September 2018), 42-48.

Wiberg, M. (2016). Interaction, new materials \& computing - Beyond the disappearing computer, towards material interactions. Materials \& Design, 90, 1200-1206. https://doi.org/10.1016/j.matdes.2015.05.032

Wiberg, M., \& Robles, E. (2010). Computational compositions: Aesthetics, materials, and interaction design. International Journal of Design, 4(2), 65-76.

\section{About the Authors}

Agnese Piselli is a Post-doc Fellow of the Department of Chemistry, Material and Chemical Engineering "Giulio Natta" (Politecnico di Milano). Her research interests focus on material selection, multi-sensory experience, smart materials and sustainable behaviour changes. She was visiting PhD at the Dyson School of Design Engineering (Imperial College). She is author of more than 20 publications on materials for design. 
Jenny Faucheu was appointed as Assistant Professor at Mines Saint-Etienne (France) after joining NIST (Gaithersburg, MD) as guest-researcher and a PhD in materials engineering from INSA-Lyon (France) on structure-properties relationships in nanocomposites. Her research focus lies at the interface between materials science and user-centred product design, covering development of new materials for creative industries, materials perception and smart materials.

Sara Colombo is Senior Research Associate at the MIT (Massachusetts Institute of Technology) Design Lab. She earned a PhD in Design at Politecnico di Milano, where she was Adjunct Professor in Interaction Design and Design \& Engineering. At MIT, she leads research projects on interaction design and emerging technologies, user experience and ethics. She published widely and chaired international conferences on these topics.

David Delafosse is Professor in Materials Science at Mines Saint-Etienne (France). He was visiting professor at Politecnico di Milano between 2013 and 2017, where he taught materials selection methods to Design \& Engineering students. He is now Vice-President for Research and Innovation at Mines Saint-Etienne.

Barbara Del Curto is full Professor at the Dpt. of Chemistry, Materials, and Chemical Engineering "Giulio Natta", School of Design, Politecnico di Milano. Her scientific activity is focused on many themes linked with traditional and functional materials, multi-sensory experience and the technology transfer in design fields. She is author of more than 100 publications on materials for design. 